\title{
Significance of arsenic resistant prokaryotes in climate change perspective
}

\author{
A.B.M.R. Islam ${ }^{1,2}$, S.A. Ahmad ${ }^{1}$, M. Alauddin ${ }^{3}$ \& K. Tazaki ${ }^{4}$ \\ ${ }^{1}$ Department of Occupational and Environmental Health, Bangladesh University of Health Sciences, Dhaka, \\ Bangladesh \\ ${ }^{2}$ Coordination of Environment and Life Line (CELL), Next International Co. Ltd, Sangenjaya, Tokyo, Japan \\ ${ }^{3}$ Department of Chemistry, Wagner College, Staten Island, New York, USA \\ ${ }^{4}$ Department of Earth Sciences, Faculty of Science, Kanazawa University, Kanazawa, Ishikawa, Japan
}

\begin{abstract}
The purpose of this study was to observe symbiotic prokaryotes under the optical and scanning electron microscope for their morphology and multiple roles including arsenic immobilization in the natural environment. Microbial mats proliferating near to the arsenic contaminated (141 to $\left.997 \mu \mathrm{g} \mathrm{L}^{-1}\right)$ tube-wells were collected for this study. The results of microscopic observation showed that the symbiotic prokaryotes in microbial mats were mainly consisting of Coccus, Bacillus, and Filamentous microbes associated with photosynthetic Cyanobacteria; enabling to accumulate high concentrations of As $\left(550 \mathrm{mg} \mathrm{kg}^{-1}\right)$. ED-XRF analysis also confirmed the presence of As in microbial mats associated with $\mathrm{Na}, \mathrm{Mg}, \mathrm{Al}, \mathrm{Si}, \mathrm{P}, \mathrm{S}, \mathrm{K}, \mathrm{Ca}, \mathrm{Ti}, \mathrm{Mn}, \mathrm{Fe}, \mathrm{Zn}$ and Sr. Henceforth, it can be concluded that the symbiotic prokaryotes can play a significant role in enabling to uptake arsenic from tube-well water, and release $\mathrm{O}_{2}$ in the ambient air simultaneously. Our findings are very encouraging for further research to promote a sustainable mitigation effort for provision of As safe drinking water and $\mathrm{CO}_{2}$ reduced safer environment.
\end{abstract}

\section{INTRODUCTION}

Arsenic (As) toxicity is a global health problem affecting millions of people through drinking water. Besides global warming is an important factor for climate change due to increasing $\mathrm{CO}_{2}$ in the atmosphere. Therefore As contamination of ground water and climate change are receiving attentions from global community as important issues of contemporary research for the sake of public health and environmental disaster. Arsenic, the metalloid poses serious health threats for human when it exceeds the WHO guideline value $10 \mu \mathrm{g} \mathrm{L}^{-1}$ in drinking water. However, some symbiotic prokaryotes are enabling to obtain energy even in an extreme or toxic environment and are intimately involved with the biogeochemical cycling of metals or metalloids for their own niche (Oremland \& Stolz, 2003). It is well known that certain prokaryotes such as Cyanobacteria are famous for their oxygenic photosynthesis (Badqer \& Price, 2003). Besides this microbial mats consisting of microbes are capable of accumulate As and produce biominerals in geo-aquaeco system (Tazaki et al., 2003; Islam et al., 2014). The aim of this study was to observe symbiotic prokaryotes under the optical and scanning electron microscope for their multiple roles; such as controls on arsenic immobilization and photo synthetic activities.

\section{METHODS AND MATERIALS}

\subsection{Materials}

Various colored microbial mats proliferating near to the arsenic contaminated tube-wells were collected from Hazigonj Upazila, a highly As contaminated areas in Bangladesh (BGS/DPHE, 2001). Tube-well waters were circum $\mathrm{pH}$ with a high concentration of As (141 to $997 \mu \mathrm{g} \mathrm{L}^{-1}$ ), much higher than that of WHO standard. A part of sample was fixed with $1 \%$ gluteraldehyde and carried to the Kanazawa University laboratory for further analysis and observations.

\subsection{Observations and analyses}

Optical microscopic observations were carried out by an epifluorescence microscope (Nikon EFD3, equipped with Digital camera: COOLPIX995). Episcopic and DAPI stained samples were observed in this study. Scanning electron microscopic (JEOL JSM$5200 \mathrm{LV}$ ) technique was applied for micro morphology of symbiotic prokaryotes. Besides this, to determine the elemental concentrations; dried microbial mats were analyzed by ED-XRF (JEOL JSX 3201). Especially, Neutron activation analytical technique was applied for determining the arsenic concentration in microbial mats. 

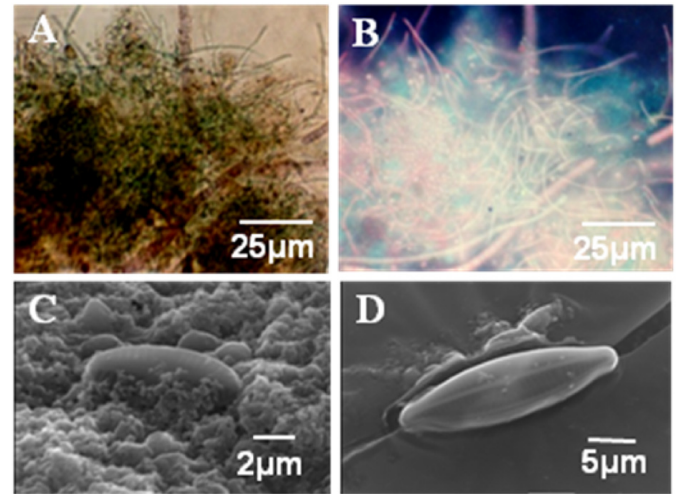

Figure 1. Micrographs show the presence of Coccus, Bacillus, Filamentous and Cyanobacteria in As rich microbial mats.

\section{RESULTS AND DISCUSSION}

\subsection{Microscopic observations}

The results of microscopic observation are shown in Figure 1. Optical micrograph indicated the colony of symbiotic prokaryotes in microbial mats, mainly consisting of autotrophs and heterotrophs, such as Coccus, Bacillus, and Filamentous microbes associated with Cyanobacteria (A). DAPI stained epifluorescence micrograph showed the fluorescent blue and red part indicating DNA in prokaryotic cells, photosynthetic pigments in chromatophores of photo-autophytes including Cyanobacteria (B). SEM micrograph confirmed the presence of As resisting Coccus and Bacillus types of prokaryotes associated with diatom in a fixed sample (C and $D)$. In this study, we found vigorous proliferations of As resistant Cyanobacteria in microbial mats, those can reduce $\mathrm{CO}_{2}$ in the environment as they are only photosynthetic prokaryotes able to produce Oxygen (Badqer \& Price, 2003). Furthermore it is reported that Cyanobacteria are responsible for roughly $10 \%$ of global photosynthetic activities (Mangan et al., (2016).

\subsection{As accumulation in microbial mats}

The profile of microbial metal accumulation is presented in Table 1. The semi quantitative analytical data showed the presence of As associated with $\mathrm{Na}$, $\mathrm{Mg}, \mathrm{Al}, \mathrm{Si}, \mathrm{P}, \mathrm{S}, \mathrm{K}, \mathrm{Ca}, \mathrm{Ti}, \mathrm{Mn}, \mathrm{Fe}, \mathrm{Zn}$ and $\mathrm{Sr}$ in all microbial mats. Intimate involvement of microbe metal interactions might play the key role in immobilizing the corresponding metals or metalloids from the As contaminated tube-well water sources (Tazaki et al., 2003). However, Neutron activation analysis (NAA) data showed a high concentration of As (550 $\mathrm{mg} \mathrm{kg}^{-1}$ ) in microbial mats, which is several thousand times higher than that of corresponding tube well water (Islam et al., 2014).
Table 1. Elemental concentrations in different microbial mats.

\begin{tabular}{|c|c|c|c|c|c|c|c|}
\hline El & D-Gy & LG & DG & LB 1 & LB 2 & LB 3 & Gy \\
\hline $\mathrm{Na}$ & nd & nd & 0.56 & nd & nd & nd & nd \\
\hline $\mathrm{Mg}$ & 1.65 & 4.72 & 1.76 & 1.41 & 1.29 & 2.15 & 1.19 \\
\hline $\mathrm{Al}$ & 5.55 & 3.18 & 8.38 & 3.00 & 3.3 & 6.24 & 4.3 \\
\hline $\mathrm{Si}$ & 40.2 & 32.86 & 51.20 & 19.34 & 28.22 & 46.08 & 28.34 \\
\hline P. & 2.63 & 3.00 & 2.84 & 4.47 & 4.35 & 3.32 & 5.63 \\
\hline $\mathrm{S}$ & 1.47 & 2.40 & 1.08 & 1.78 & 3.62 & 1.40 & 2.64 \\
\hline $\mathrm{K}$ & 7.56 & 3.64 & 7.99 & 4.99 & 9.17 & 7.63 & 6.86 \\
\hline $\mathrm{Ca}$ & 13.83 & 10.98 & 7.42 & 17.28 & 17.03 & 7.77 & 12.45 \\
\hline $\mathrm{Ti}$ & 2.71 & 2.88 & 2.47 & 1.46 & 2.95 & 3.33 & 3.37 \\
\hline Mn & 0.93 & 4.00 & 0.32 & 0.86 & 1.30 & 1.11 & 2.66 \\
\hline $\mathrm{Fe}$ & 22.89 & 30.05 & 15.95 & 44.43 & 28.22 & 20.35 & 31.23 \\
\hline $\mathrm{Zn}$ & 0.33 & 1.89 & nd & 0.36 & 0.18 & 0.16 & 0.68 \\
\hline As & 0.16 & 0.26 & 0.02 & 0.46 & 0.21 & 0.18 & 0.50 \\
\hline $\mathrm{Sr}$ & 0.1 & 0.17 & nd & 0.15 & 0.12 & 0.08 & 0.15 \\
\hline & 100 & 100.03 & 99.99 & 99.99 & 99.96 & 99.89 & $\begin{array}{l}100 \\
w t \%\end{array}$ \\
\hline
\end{tabular}

El; Elements, D-Gy; Dim Grey, LG; Light Green, DG; Deep Green, LB 1; Light Brown 1, LB 2; Light Brown 2, LB 3; Light Brown 3, Gy; Grey, nd; not detected.

\section{CONCLUSIONS}

Symbiotic prokaryotes can play a significant role in enabling to uptake arsenic from well water, and release of $\mathrm{O}_{2}$ in the atmosphere. Further research are needed to develop a sustainable mitigation effort for provision of As free safe drinking water and $\mathrm{a} \mathrm{CO}_{2}$ reduced safer environment.

\section{ACKNOWLEDGEMENTS}

We thank Ministry of Education, Science and Culture, Japan for supporting this study. We are thankful to Dr. Wahid Uddin Ahmed and GETE Research Center, Bangladesh for additional support.

\section{REFERENCES}

BGS/DPHE 2001. Arsenic contamination of groundwater in Bangladesh, Volume1: ReportWC/00/19, Keyworth: British Geological Survey.

Badqer, M.R. \& Price, G.D. 2003. $\mathrm{CO}_{2}$ concentrating mechanisms in Cyanobacteria: Molecular components, their diversity and evolution, J. Exp. Biol. 54(383): 609-622.

Islam, A.B.M.R., Jalil, M.A. \& Tazaki, K. 2014. Roles of microbial community on arsenic removal in drinking water. Chem. Express 3(3): 85-96.

Mangan, N.M., Flamholz, A., Hood, R.D., Milo, R. \& Savage, D.F. 2016. $\mathrm{pH}$ determines the energetic efficiency of the cyanobacterial $\mathrm{CO}_{2}$ concentrating Mechanism, Proc. Natl. Acad. Sci. USA. 113(36): E5354-E5362.

Oremland, R.S. \& Stolz, J.F. 2003. The ecology of arsenic, Science 300: 939-944.

Tazaki, K., Islam, A.B.M.R., Nagai, K. \& Kurihara, T. 2003. $\mathrm{FeAs}_{2}$ biomineralization on encrusted bacteria in hot springs: an ecological role of symbiotic bacteria, Can. J. Earth Sci. 40: 1725-1738. 